\title{
EVALUASI APLIKASI EXPLOID WIFI DI TINGKAT AVAILABILITY DAN VULNERABILITY
}

\author{
Timur Dali Purwanto \\ Fakultas Vokasi, Program Studi Teknik Komputer \\ Universitas Bina Darma \\ Email: timoerok@gmail.com
}

\author{
Alek Wijaya \\ Fakultas Ilmu Komputer, Program Studi Teknik Informatika \\ Universitas Bina Darma \\ Email: allec_wj@yahoo.com
}

\begin{abstract}
ABSTRAK
Pada sistem jaringan wireless sering terjadi masalah yaitu salah satunya keamanan wifi yang menggunakan keamanan WPA, WPA2, dan WEP yang ditinjau dari vulneravility. Karena teknologi wireless memanfaatkan frekwensi tinggi untuk menghantarkan sebuah komunikasi, maka kerentanan terhadap keamanan juga lebih tinggi dibanding dengan teknologi komunikasi yang lainnya. Sekarang ini sudah banyak tool aplikasi exploit wifi yang di gunakan oleh hacker atau attacker salah satunya tool Reaver dan tool Aircrack dalam system operasi kali linux, dari kedua tool tersebut peneliti ingin mencari perbandingan dari tingkat availability. Karena kedua tool tersebut menurut peneliti adalah tool yang terbaik saat ini. Dalam penelitian ini parameter yang akan di ukur adalah seberapa capat waktu ackes ke jaringan wifi, seberapa cepat menembus keamanan wifi, dan berapa besaran biter yang di dapat. Dari hasil penelitian dan uji coba maka di simpulkan bahwa untuk segi kecepatan aircrack yang lebih cepat untuk memecah password karena bruteforce dengan wordlist, reaver langsung scanning password wifi namun memakan waktu sangat lama hampir 13 jam untuk waktu terlama
\end{abstract}

Kata kunci: tool reaver dan aircrack, avability dan vurnability bruteforce, wordlist.

\begin{abstract}
In wireless network systems often occur a problem that is one of the wifi security that uses the security of WPA, WPA2, and WEP in terms of vulneravility. Because wireless technology utilizes high frequencies to deliver a communication, the vulnerability to security is also higher than with other communications technologies. Now there are many wifi exploit application tools that are used by hackers or attackers one of the tools reaver and Aircrack tool in linux operating system, from both tools the researchers want to find a comparison of the availability level. Because the two tools are according to researchers is the best tool today. In this study the parameters to be measured is how much time to wifi ackes wifi network, how fast penetrate wifi security, and how the amount of biter in the can. From the results of research and experiments it is concluded that for the speed facets of aircrack faster to break the password because bruteforce with wordlist, reaver directly scanning the wifi password but take very long time almost 13 hours for the longest time.
\end{abstract}

Keywords: reaver and aircrack tool, avability and vurnability bruteforce, wordlist.

\section{PENDAHULUAN}

Pada saat berasosiasi menggunakan wireless yang terkoneksi dengan media access point menggunakan security WPA apakah aman dari serangan hacker? Ternyata WPA, WEP dan WPA2 masih ada yang mengklaim masih di bobol. [1] menyatakan WPA, WEP dan WPA2 pernah di bobol oleh attacker, dalam artian belum aman. Bagaiman cara mengamankan serangan tersebut? Sebelum melakukan pengamanan terlebih dahulu mengetahui bagaimana cara attacker melakukan penyerangan kejaringan wifi menggunakan tools yang sering digunakan para attacker atau cracker khususnya dalam jaringan wifi tool tersebut adalah Reaver, aircrack, macchanger, Crunch, Wash, Fern Wifi Cracker, oclHashcat, Wireshark,Wifite, dan terahir Pixiewps. Dari beberapa tool tersebut ada dua tool yang akan di pakai dan di perbandingkan.

[2] Aircrack adalah salah satu alat yang paling populer untuk WEP / WPA / WPA2 retak. The Aircrack-ng suite berisi alat untuk menangkap paket dan jabat tangan, de-authenticate terhubung klien dan menghasilkan lalu lintas dan alat-alat untuk melakukan kekerasan dan serangan kamus. [3] Reaver 
merupakan tool yang terbaru untuk cracking wifi dengan WPA protected dan ini adalah salah satu tool yang digunakan kedua tool tersebut yang akan di gunakan untuk melakukan exploitasi wifi. Dari kedua tool tersebut mana yang terbaik? Berdasarkan dari pertanyaan dan latar belakang yang diuraikan diatas, maka peneliti tertarik untuk melakukan perbandingan suatu perangkat aplikasi exploit pada jaringan wifi yang menggunakan keamanan WPA, WPA2 dan WEP.

\section{METODOLOGI PENELITIAN}

Dalam penelitian ini menggunakan metode penelitian Action Research atau metode tindakan. Penelitian tindakan merupakan penelitian yang bertujuan mengembangkan metode kerja yang paling efisien, sehingga biaya produksi dapat ditekan dan produktifitas lembaga dapat meningkat [4].

Action Research menurut Davison, dkk. (2004) [5] yaitu penelitian tindakan yang mendeskripsikan, menginterprestasikan dan menjelaskan suatu situasi sosial atau pada waktu bersamaan dengan melakukan perubahan atau interversi dengan tujuan perbaikan atau partisipasi. Adapun tahapan penelitian yang merupakan bagian dari Action Research ini yaitu:

a) Melakukan Diagnosa (Diagnosing) Peneliti melakukan diagnosa terhadap sistem jaringan wireless.

b) Membuat Rencana Tindakan (Action Planing) Peneliti melakukan rencana tindakan yang akan dilakukan pada jaringan wifi dengan membuat pengujian sistem keamanan jaringan yang menggunakan metode exploitasi.

c) Melakukan Tindakan (Action Taking) Peneliti mengimplementasikan rencana dengan tindakan yang telah dibuat dengan menjalankan tahapan-tahapan mengikuti testing terhadap jaringan wifi untuk mendpatkan celah.

d) Dari sistem jaringan wifi dan juga mendapatkan analisis dari hasil pencegahan dari Reaver dan Aircrack.

e) Melakukan Evaluasi (Evaluating )

Peneliti melaksanakan evaluasi hasil dari penetrasi dan pencegahan yang telah dilakukan pada jaringan wifi.

f) Menentukan Pembelajaran (Specifying Learning )

Melakukan review tahapan-tahapan yang telah berakhir dan mempelajari kriteria celah keamanan dan cara menanganinya.

\subsection{Metode Pengumpulan Data}

Dalam penelitian ini akan menggunakan beberapa metode pengumpulan data, berikut adalah metode pengumpulan akan digunakan :

a) Pengamatan (Observasi). Data dikumpulkan untuk mendapatkan hasil yang jelas tentang penelitian ini dalam melakukan pengamatan tentang exploitasi wifi.

b) Pengujian (Testing). Data diperoleh dari pengujian exploitasi wifi yang dilakukan.

\subsection{Kerangka Kerja}

Tahapan yang terpenting dalam satu penelitian adalah menyusun kerangka kerja. Kerangka kerja yang terkonseptualisasi dengan baik dapat mengetahui pada gejala-gejala pengamatan, yang pernah dijelaskan oleh W Gulo [6] Konseptualisasi adalah proses pembentukan konsep dengan bertitik tolak pada gejala-gejala pengamatan. Kerangka Kerja yang tergambar dibawah dapat dijelaskan sebagai berikut:

a) Sebuah jaringan wifi yang akan menjadi objek utama untuk melakukan

b) penetrasi pada penelitian ini.

c) Melakukan diagnosa pada jaringan untuk mengetahui bagian-bagian dari jaringan yang mempunyai celah keamanan, sehingga peneliti dapat menentukan tempat yang tepat untuk dilakukan penetrasi.

d) Didalam penelitian ini akan dilakukan pengujian internal. Pada pengujian internal ini dilakukan penetrasi sesudah proses autentikasi wireless dengan tujuan mencari celah keamanan yang bisa dieksplorasi oleh pengguna, untuk pengujian secara internal ini peneliti melakukan serangan yang bersifat pasif dimana serangan tidak mempengaruhi kinerja sistem. 
e) Pada tahap Action Taking, tindakan yang akan dilakukan adalah pengujian penetrasi menggunakan tools reaver dan aircrack Pengujian akan dilakukan kedua tools tersebut untuk mendapatkan hasil dari keamanan jaringan wifi dan mendapat perbandingan dari kedua tool.

f) Evaluasi pada tahapan ini peneliti akan melakukan sebuah kesimpulan mengenai bagaimana cara mengetahui celah dari suatu sistem wifi yang ada dan membuat suatu laporan dari hasil pengujian jaringan.

g) Dokumentasi dan pelaporan meliputi statistik persentase keberhasilan dalam teknik pengujian dan tabel hasil pengujian.

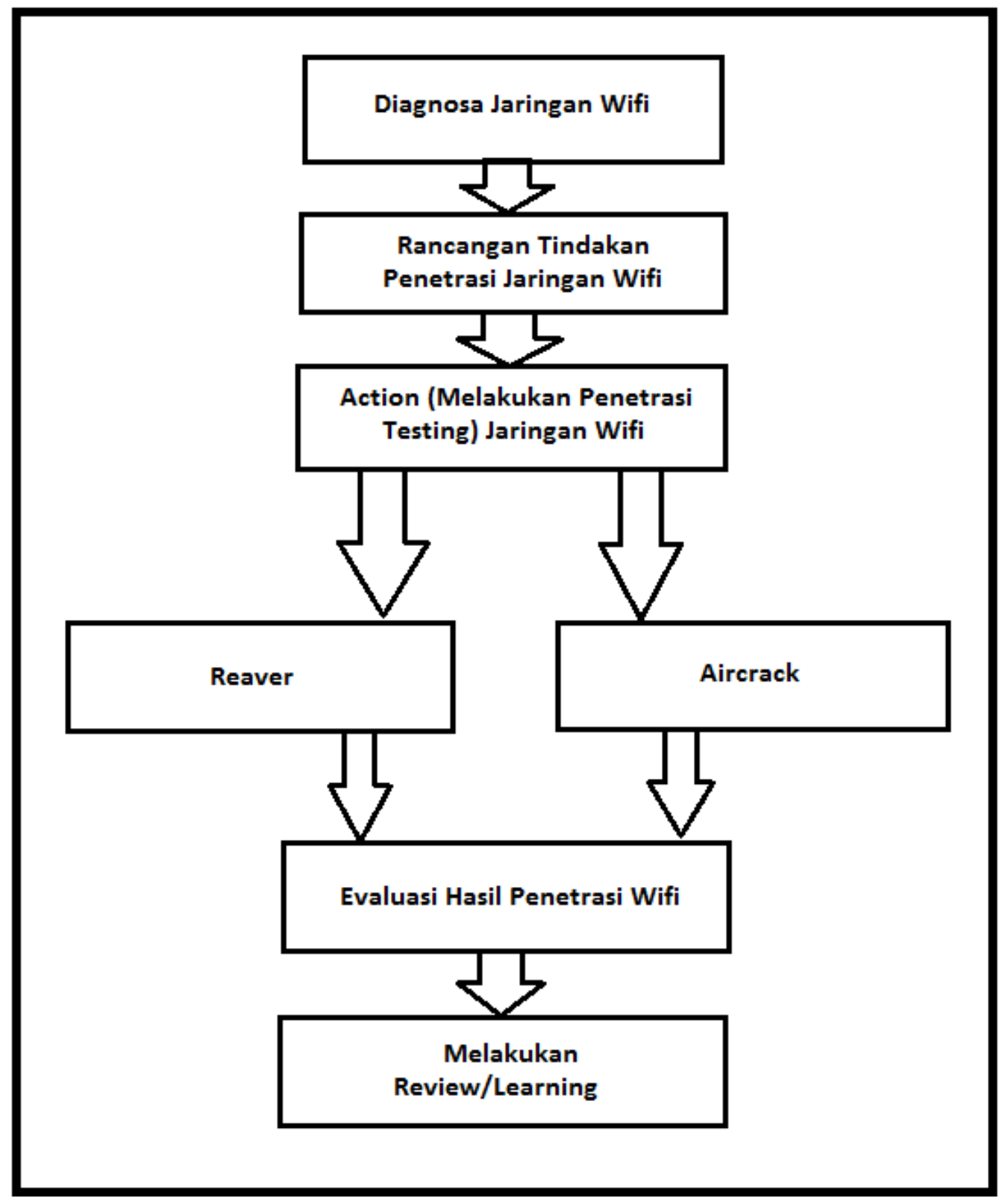

Gambar 1. Kerangka Berpikir 


\section{HASIL DAN PEMBAHASAN}

\subsection{Hasil}

Hasil ini berdasarkan hasil uji coba reserch di laboratorium dengan menggunakan perangkat atau alat sesuai dengan kerangka berpikir, dengan jarak $8 \mathrm{~m}$ dari AP target dan frekuensi sebesar 2,4 MHz dengan aliran bandwith sebesar 2 Mbps menggunakan aplikasi aircrack-ng dan aplikasi reaver yang menghasilkan parameter yang telah di uji dari hasil uji tersebut diambil nilai rata-rata tercepat (accessb Time dan Crack Time) atau tebesar (bandwitdth).

Peneliti melakukan evaluasi dari hasil penetrasi dan akan melihat hasil dari perbandingan dari kedua aplikasi yang di uji yaitu aplikasi aircrack dan reaver dapat dilihat dari ketiga tabel di bawah ini.

Tabel 1. Hasil uji coba menggunakan aircrack-ng

\begin{tabular}{cccccl}
\hline No & Bandwith (bps) & Bandwith Nyata (bps) & Crack Time (s) & Access Time (s) & Keterangan \\
\hline 1 & 2000 & 1622 & 10 & 120 & WPA \\
2 & 2000 & 1532 & 15 & 6 & WPE \\
3 & 2000 & 217 & 25 & 600 & WPA2 \\
4 & 2000 & 7 & 10 & 18 & WPE \\
5 & 2000 & 11 & 10 & 24 & WPA2 \\
6 & 2000 & 29 & 10 & 480 & WPA \\
7 & 2000 & 2580 & 10 & 780 & WPA2 \\
8 & 2000 & 2304 & 10 & 6 & WPA2 \\
9 & 2000 & 2651 & 10 & 120 & WPA \\
10 & 2000 & 2311 & 851 & 1080 & WPE \\
\hline \multicolumn{7}{r}{} & Rata-rata & $\mathbf{1 3 2 6 , 4}$ & $\mathbf{9 6 , 1}$ & $\mathbf{3 2 3 , 4}$ & \\
\hline
\end{tabular}

Tabel 2. Hasil uji coba menggunakan tools reaver

\begin{tabular}{|c|c|c|c|c|c|}
\hline No & Bandwith (bps) & Bandwith Nyata (bps) & Crack Time (s) & Access Time (s) & Keterangan \\
\hline 1 & 2000 & 176 & 1932 & 38 & WPA \\
\hline 2 & 2000 & 1931 & 45631 & 18 & WPE \\
\hline 3 & 2000 & 217 & 31231 & 1500 & WPA2 \\
\hline 4 & 2000 & 253 & 16831 & 8 & WPE \\
\hline 5 & 2000 & 11 & 13231 & 38 & WPA2 \\
\hline 6 & 2000 & 29 & 2232 & 12 & WPA \\
\hline 7 & 2000 & 645 & 6031 & 2700 & WPA2 \\
\hline 8 & 2000 & 1821 & 5232 & 120 & WPA2 \\
\hline 9 & 2000 & 764 & 9631 & 24 & WPA \\
\hline 10 & 2000 & 2301 & 3271 & 38 & WPE \\
\hline \multicolumn{2}{|r|}{ Rata-rata } & 814,8 & 13525,3 & 449,6 & \\
\hline
\end{tabular}

Tabel 3. Perbandingan dua tools

\begin{tabular}{lcccc}
\hline \multicolumn{1}{c}{ INDUKSI } & TOOLS & WPA & WEP & WPA2 \\
\hline Kecepatan Akses (Access Time) & Aircrack & 240 & 240 & 325,5 \\
& Reaver & 24,667 & 24,667 & 1089,5 \\
Bandwith & Aircrack & 1434 & 1434 & 1278 \\
& Reaver & 323 & 323 & 673,5 \\
\hline \multicolumn{1}{c}{ INDUKSI } & TOOLS & WPA & WEP & WPA2 \\
\hline Waktu pembobolan & Aircrack & 10 & 10 & 13,74 \\
(Crack Time) & Reaver & 4598,3 & 4598,3 & 13931,25 \\
\hline
\end{tabular}

\subsection{Pembahasan}

Berdasarkan hasil dari penelitian dimana terdapat 3 (tiga) Perbandingan dua aplikasi dalam bentuk tabel berdasarkan parameter statement untuk rekomendasi berdasarkan hasil fakta saat melakukan uji penestrasi. 
Tabel 1 di merupakan hasil uji coba menggunakan aircrack-ng yang dilakukan sebanyak 10 kali percobaan. Dimana rata-rata bandwith nyata digunakan sebesar 1.326,4 bps yang kurang dari 2 Mbps. Crack Time merupakan kemampuan (availbility) tools dalam melakukan bobol password yang dengan kecepatan rata-rata sebesar 96,1 s dan pada access time digunakan untuk kemampuan meretas sistem jaringan wireless dengan kecepatan sebesar 323,4 s. Berdasarkan keterangan hasil uji dapat disimpulkan bahwa jaringan wariless sangat rentan (vulnerability) atau mudah di hack oleh hacker dengan kecepat Crack Time $10 \mathrm{~s}$ dan access time nya dengan kecepatan $6 \mathrm{~s}$ yang dibandingan hasil ujian lainnya

Tabel 2 adalah hasil uji coba menggunakan aplikasi reaver yang dilakukan sebanyak 10 kali percobaan. Dimana rata-rata bandwith nyata digunakan sebesar 814,8 bps yang kurang dari 2 Mbps. Crack Time merupakan kemampuan (availbility) tools dalam melakukan bobol password yang dengan kecepatan rata-rata sebesar 13525,3 s dan pada access time digunakan untuk kemampuan meretas sistem jaringan wireless dengan kecepatan sebesar 449,6 s. Berdasarkan keterangan hasil uji dapat disimpulkan bahwa jaringan wariless sangat rentan atau mudah di hack oleh hacker dengan kecepat Crack Time $1932 \mathrm{~s}$ dan access time nya dengan kecepatan 8 s yang dibandingan hasil ujian lainnya, tetapi bila dibandingkan tools rever dan tools aircrack-ng, tools rever lebih lamban.

Dari hasil tabel 3 berdasarkan nilai rata-rata kedua tools yang di uji menghasilan, induksinya adalah bandwith, access time, dan Crack Time. Yang di nilai dari availability atau (kemampuan) reaver lebih simpel dalam pengerjaan. Karena tidak melakukan bruteforce, namun memakan waktu lama untuk memecahkan password wifinya \pm 5 jam kalu di jam kan. dan vulnerability (kerentanan) password udah di scanning. Sedangkan aircrack dalam pengerjaanya sedikit lebih rumit karena harus melakukan bruteforce namun saat memecah password lebih cepat karena sudah melakukan bruteforce dengan wordlist \pm 3 jam di wpa dilihat dari Crack Time. Dari kedua tools bandwith yang di dapat hampir sama, namun dilihat dari waktu pembobolan lebih cepat aircrack dari pada reaver.

Cara mengatasi biar sulit untuk di bobol pakailah wpa2 enterprice dan pakai password dengan kombinasi yang susah untuk di tebak karna kalau memakai kombinasi yang mudah di tebak atau biasa, mudah sekali di pecah dengan cara bruteforce dengan wordlist

\section{KESIMPULAN}

Adapun hasil dari analisis penelitian ditarik beberapa kesimpulan sebagai berikut :

a) Dari kedua aplikasi yang telah diuji untuk melihat tingkat availability dan vulnerability, maka disimpulkan bahwa aplikasi aircrack lebih cepat untuk menembus password wifi, namun aircrack lebih rumit dibandingkan dengan reaver karena harus melakukan bruteforce dengan wordlist. Sedangkan reaver langsung melakukan scanning password tapi membutuhkan waktu yang sangat lama.

b) Dari segi kerentanan wifi yang menggunakan wpa2 lebih sulit untuk ditembus dibandingkan dengan wifi yang menggunkana keamanan wep dan wpa. Namun untuk lebih bagus lagi wifi yang menggunakan wpa2 lebih baik menggunakan password dengan kombinasi yang rumit agar sulit di pecahkan

c) Dengan penjelasan ini, pengguna internet yang menggunakan wifi mulai sadar dan mulai merubah password dengan teknologi terbaru dan juga mulai menggunakan mikrotik. Semakin banyak pengguna wifi, semakin lambat juga koneksi internet.

\section{DAFTAR PUSTAKA}

[1] Davison, R. M., Martinsons, M. G., Kock N., (2004), Journal : Information Systems Journal : Principles of Canonical Action Research 14, 65-86.

[2] Hurley Crish, R,F,D,B. (2007). ”WarDriving and Wireless Penetration Testing”, Syngress Publishing, Inc. Rockland.

[3] Marco Alamanni (2015). “Kali Linux Wireless Penetration Testing Essentials”, Packt Publishing Ltd. Birmingham B3 2PB, UK.

[4] Madya, S, (2006) Teori dan Praktik Penelitian Tindakan (Action Research), Alfabeta: Bandung.

[5] Kennedy, David., O’Gorman, Jim., Kearn, Devon., Aharoni, Mati (2011) .Metasploit The Penetration Tester's Guide. HD MOORE. San Francisco. 
Jurnal SIMETRIS, Vol 8 No 2 November 2017

ISSN: 2252-4983

[6] Gulo, W. (2010). ” Metodologi Penelitian”. PT. Grasindo. Jakarta. 